\title{
Environmental Vulnerability by Floods and Occupation of Permanent Preservation Area: An Approach about Three Cities of Midwest of Brazil
}

\author{
Greyce Bernardes de Mello Rezende ${ }^{1} \&$ Telma Lucia Bezerra Alves ${ }^{2}$ \\ ${ }^{1}$ University Federal of Mato Grosso, Brazil \\ ${ }^{2}$ Federal Institute of Alagoas, Brazil \\ Correspondence: Greyce Bernardes de Mello Rezende, University Federal of Mato Grosso, Brazil. E-mail: \\ greycebernardes@yahoo.com.br
}

Received: November 4, 2016

Accepted: March 7, 2017 Online Published: March 30, 2017

doi:10.5539/jsd.v10n2p45

URL: https://doi.org/10.5539/jsd.v10n2p45

\begin{abstract}
The purpose of this article is to identify the areas of environmental vulnerability by flooding in urban areas of the municipalities of Barra dos Garças - MT, Pontal do Araguaia - MT and Aragarças - GO; and demarcate the occupations in permanent preservation areas (PPAs) in the study area. The methodology uses variables such as time series of maximum quotas of the Araguaia River, from 1968 to 2014, the frequency of those floods, as well as the local level curves. From the junction of these data, it was stipulated the levels of environmental vulnerability by floods in five levels: very high, high, medium, low and very low. The results indicate that areas with very high vulnerability correspond to approximately 1,58 square kilometers which equals to $0.5 \%$ of the total area studied; the high vulnerability areas, have only 3.19 square kilometers, corresponding to $1 \%$ of the area; the medium vulnerability areas have 7.66 square kilometers, which corresponds to $2.41 \%$ of the area; low vulnerability areas, have 11.18 square kilometers of extension relating to $3.52 \%$ of the area; and finally the remainder of the study area was characterized as very low vulnerability. After this mapping, it was found by satellite imaging from Google earth software dated 2014, the main occupations in PPAs. The main uses and occupations refer to human activities related to tourism, as well as commercial, residential and industrial buildings. It was found that it is of salutary importance that the Government enforces the fulfillment of the restrictions set out in the Forest Code, preventing that more occupations occur in PPAs and areas subject to flooding. Moreover, the mapping of areas of flooding is also a tool for future public policies that aim to guide the recommended areas to urban expansion, as well as ordering the use and occupation of land by developing zoning.
\end{abstract}

Keywords: environmental vulnerability, inundation, permanent preservation area

\section{Introduction}

The river-city relationship is still marked by some problems: one of them relates to the regulation of Permanent Preservation Areas in urban areas described in the Forest Code (Federal Law N $\mathrm{N}^{\mathrm{o}} 12.651$ / 2012). This law describes the consolidated areas in Permanent Preservation Areas (PPAs), regulating on land tenure issues, both social interest and specific interest. However, the standard did not have the expected effectiveness because, paradoxically, the areas where the law does not allow regular occupation, are often the target of occupation by the population that has no access to the formal housing market.

Therefore, there is a duality between "legal city" where focus public investment, and the "illegal" city, where quickly growing informal occupations dominate in precarious and of environmental vulnerability areas (Maricato, 2001).

It was found that real estate speculation in areas with large populations, because of the shortage of real estate, encourages the practice of illegal occupation by the low-income population that is sometimes excluded from the formal real estate market. These occupations often occur in valley bottoms, subject to flooding or areas of environmental protection. (Gamba \& Ribeiro, 2012) 
Another point to be mentioned, are the many consequences of the urbanization of the watershed and the banks of urban rivers, which reflect in the management of rainwater and more frequent and intense floods. Situations of risk of flooding and flooding in cities are directly related to the technical capacity of intervention in the drainage system and in interventions of the riverbanks, but also permeates for vulnerability situations that urban context intensifies.

In this context, the mapping of environmental vulnerability areas as the flood, based on the determination of flooding spots, it sought meet and assist a demand in the water planning and management in the urban environment being very relevant to the sustainable development of cities.

In this sense, the flood spots can be used as an important tool for urban planning, land use planning, as well as urban drainage master plans. They consist in the preparation of maps that have as final product the representation of the most affected regions in the case of flooding.

Thus, this article aims to identify the areas of environmental vulnerability as the flooding in urban areas of the municipalities of Barra do Garças - MT, Pontal do Araguaia - MT and Aragarças - GO and demarcate the occupations in permanent preservation areas in the study area.

\section{Materials and Methods}

The study area covers the urban spot formed by three municipalities, namely: Aragarças, Goiás State; Pontal do Araguaia and Barra do Garças in Mato Grosso State, cut by rivers Araguaia and Garças. Map 1 shows the location of the study area.

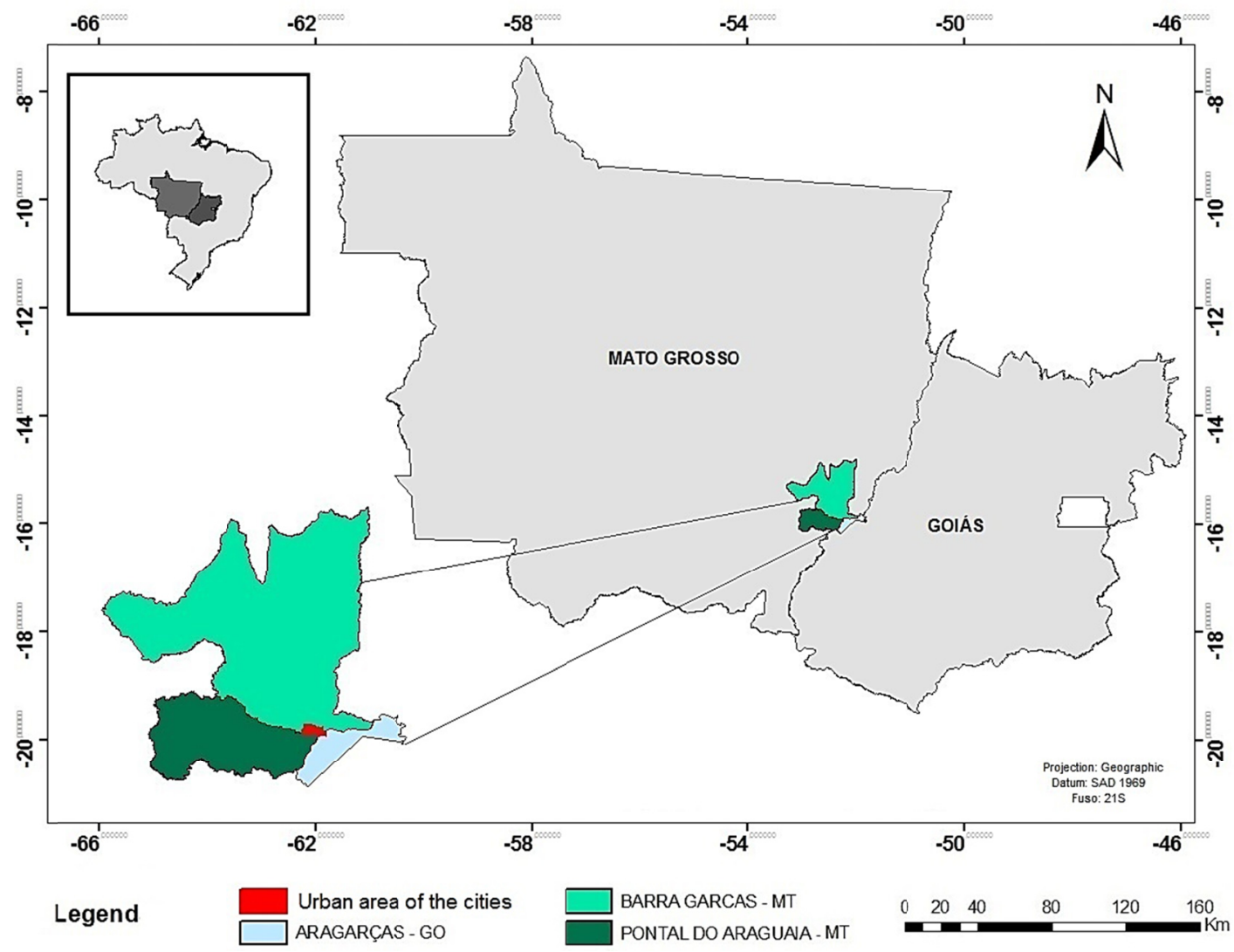

Map 1. Location map of cities

Source: Elaborated by author

Figure 1 below illustrates the relationship of the cities with the Araguaia and Garças Rivers. 


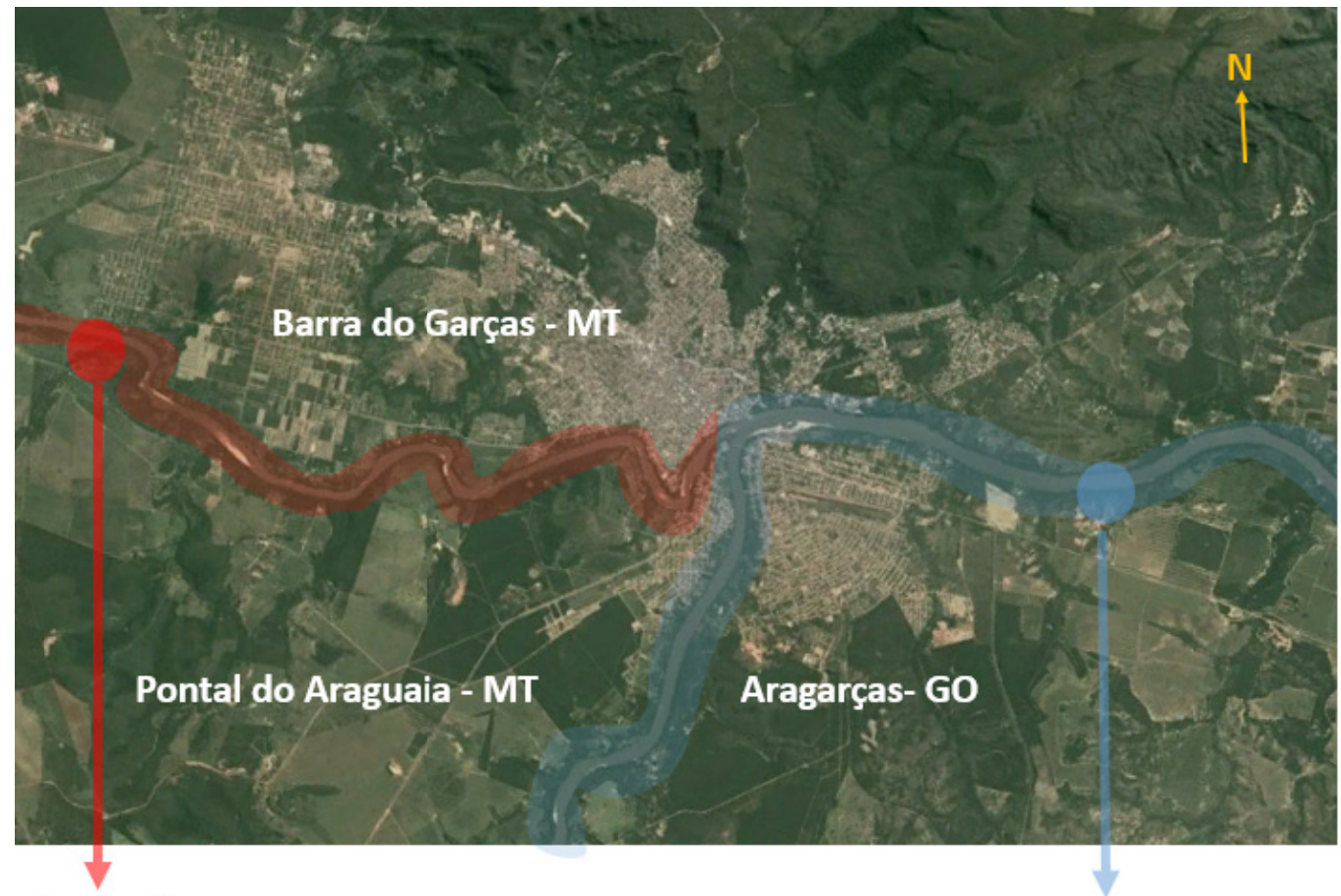

\section{Garças river}

Araguaia river

Figure 1. Delimitation of the study area, whereas cities and Araguaia and Garças Rivers

Source: Elaborated by the first author from satellite image from Google Earth 2014 software.

The hydrologic regime in the study area is well defined, with a dry period ending in September / October and a rainy period when higher rainfall occurs between December and March (Figure 1). Because of this regular rainfall, flood periods of the basins are well defined, taking place from January to March.

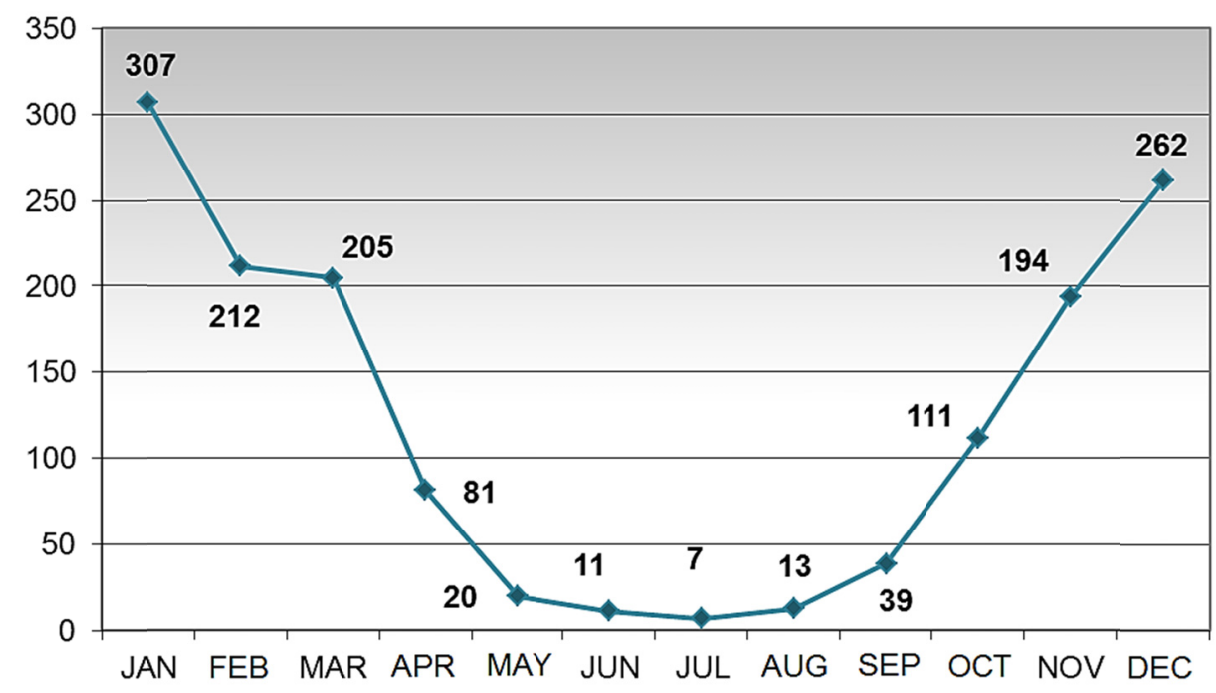

Graph 1. Average rainfall per month (mm / month) from 1984 to 2014

Source: Prepared by the first author from the historical data of the National Institute of Meteorology

According to the historical series of maximum quotas of the Araguaia River, provided by the "Agência Nacional de Águas - ANA" (National Water Agency), the largest floods occurred in February 1980 and 2004, as can be 
seen in Graph 2. Some older residents also report a very intense flood in 1942, when Araguaia waters invaded the old city center.

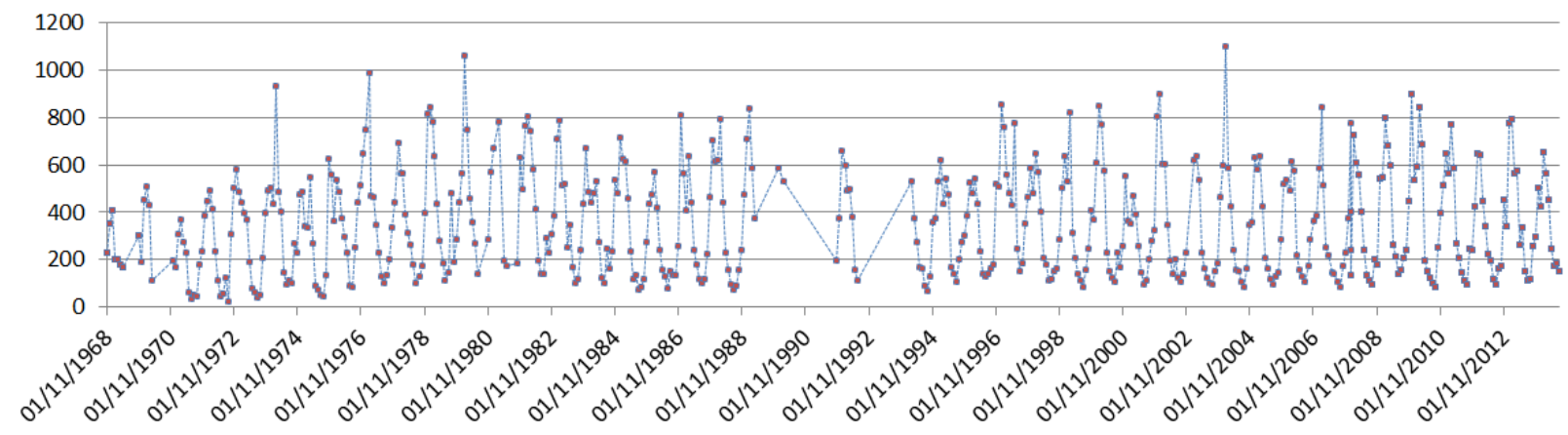

Graph 2. Maximum quotas of the Araguaia River from 1968 to 2014

Maximum quota $(\mathrm{cm})$

Source: Prepared by the first author through the data fluviometric station $n^{\circ} .24700000$ provided by "ANA"

By combining data with the maximum quotas of the Araguaia River (Graph 2) and local levels curves flood spots maps with the following intervals were made: Annual flooding frequency, corresponding to the interval between the main channel of the river and flood line annual frequency corresponding to a maximum quota of up to $550 \mathrm{~cm}$; flooding frequency $\leq \mathbf{2}$ years corresponding to the interval between the flood line of annual frequency and the frequency flood line of 2 years, which corresponds to a maximum quota from 550 to $800 \mathrm{~cm}$; flooding frequency $\leq \mathbf{1 0}$ years, corresponding to the interval between the frequency flood line of 2 years and time frequency flood line of 10 years, which is corresponding to a maximum quota of 800 to $1050 \mathrm{~cm}$; flooding frequency $\leq \mathbf{2 4}$ years, corresponding to the interval between time frequency flood line of 10 years and time frequency flood line of 24 years, which corresponds to a maximum quota 1050-1300 cm; flooding frequency > 24 years, corresponding to the area outside the frequency flood line of 24 years, or maximum quota above $1300 \mathrm{~cm}$.

From these data, the environmental vulnerability levels, as the risk of flooding, were:

a) VERY HIGH Environmental Vulnerability by flood - annual flooding frequency and quota of up to $550 \mathrm{~cm}$;

b) HIGH Environmental Vulnerability by flood - flooding frequency 1 to 2 years of flooding and quota 550-800 $\mathrm{cm}$;

c) MEDIUM Environmental Vulnerability by flood - flooding frequency between 2 to 10 years and quota 800-1050 cm;

d) LOW Environmental Vulnerability by flood - flooding frequency between 10-24 years and quota 1050-1300 $\mathrm{cm}$;

e) VERY LOW Environmental Vulnerability by flood - flooding frequency over 24 years and quota above 1300 $\mathrm{cm}$.

Table 1 shows the classification and representation of the variation of the areas mapped by the corresponding color as a defined scale for this study. 
Table 1. Classification and Representation of the Environmental Vulnerability levels by floods

\begin{tabular}{l|l}
\hline \multicolumn{1}{c}{$\begin{array}{c}\text { ENVIRONMENTAL VULNERABILITY } \\
\text { LEVELS BY FLOODS }\end{array}$} & COLORING \\
\hline Very high & \\
High & \\
Medium & \\
Low & \\
Very low & \\
\hline
\end{tabular}

After completion of this mapping, the main occupations existing in Permanent Preservation Area by using satellite image Google earth software 2014 were observed; and the assumption used to determine these areas: the distance of 100 (one hundred) meters of watercourses, as provided in Article 4, I, "c" of the Forest Code - Law n ${ }^{\circ}$. 12.651 / 2012 (Brasil, 2012). (Note 1)

\section{Results and Discussion}

\subsection{Environmental Vulnerability by Floods}

The environmental vulnerability, by floods was analyzed from a map that could represent the spatial extent of the flood events, considering the frequency of them.

From SRTM radar images with a resolution of $90 \mathrm{~m}$, an extraction was made of level curves every $2.5 \mathrm{~m}$ and the drainage network, as well as generating triangular grid to identify the altitude quotas. Thereafter, a reclassification of flood spots according to the predetermined quotas was made. These quotas were drawn from analysis of the time series of maximum quotas affected by the river, considering the frequency in which they occurred. (Map 2).

The maximum quotas analyzed refer to fluviometric station 27400 , located right after the meeting of the Garças and Araguaia rivers. Importantly, in the study area, only this station collects data related to maximum quotas. Thus, for the preparation of map 2, it was necessary to make an extrapolation of flood spots upstream of station 27400 .

It is noteworthy thatin order to obtain more accurate flood spots above the meeting of the waters, it would be necessary to have data of maximum quotas, which was not possible since the existing stations at these sites do not collect these data. 


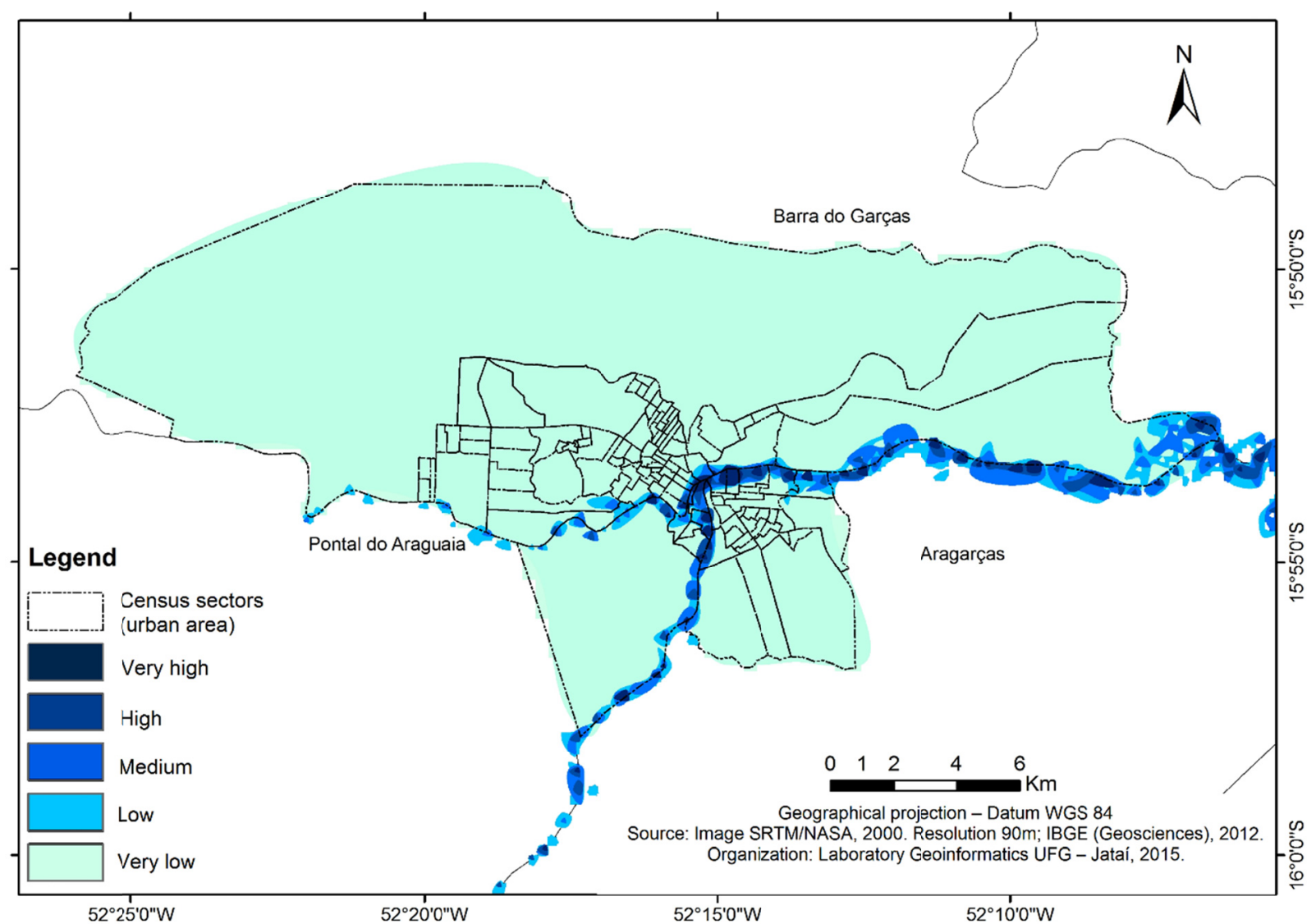

Map 2. Physical-spatial vulnerability to flooding

The areas at risk of flooding vary according to the frequency of occurrence of an event in a particular extension area. As shown on the map, very high vulnerability areas which have annual flood frequency and corresponds to small areas: approximately 1,58 square kilometers which equals $0.5 \%$ of the total area studied. These areas are located mostly on the banks of the Araguaia River, especially after the meeting of the waters with the Garças River.

As for the high vulnerability areas, which are observed to have a frequency of 1 to 2 years do not correspond to a great extent of areas. They have only 3,19 square kilometers, which corresponds to $1 \%$ of the studied area.

There are, in these two flood spots in these, areas along the waterfront, after the meeting of the waters of Garças and Araguaia rivers. Figures 2, 3 and 4 show the development of the river flooding. Figure 2 shows the Araguaia River in its lower bed; Figure 3 shows the river with quota characterized as very high vulnerability (flooding of March 2015) and Figure 4 shows the river with quota for high vulnerability range. It is observed that, despite floods occur with high frequency, the damage to the population is not so significant considering that they reach areas that are sparsely occupied.

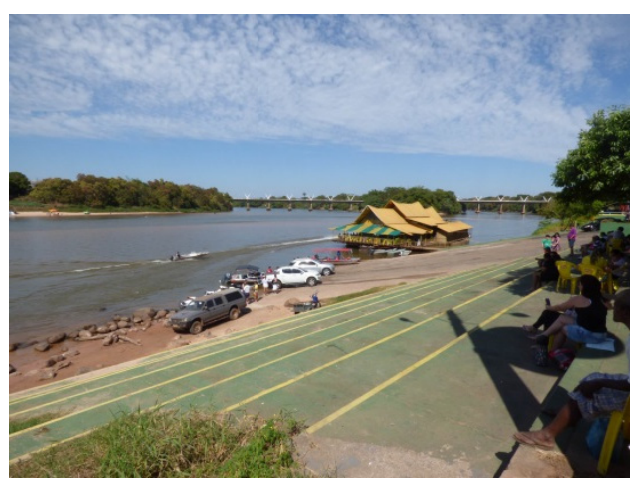

Figure 2. Araguaia River in its lower bed - July 2014

Source: Photo of the first author 


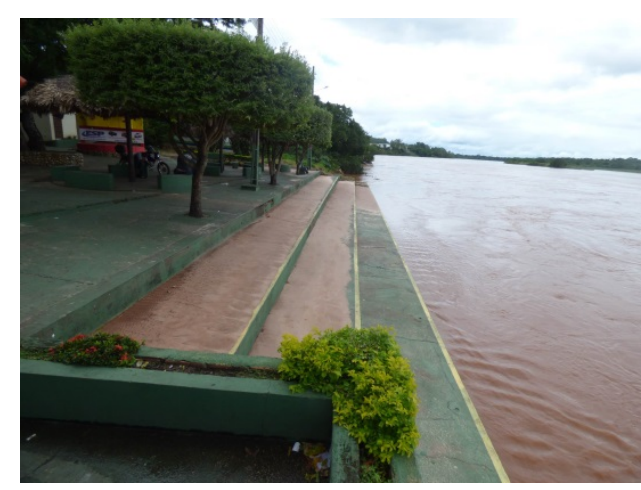

Figure 3. Flooding of Araguaia - Mar 2015

Source: Photo of the first author

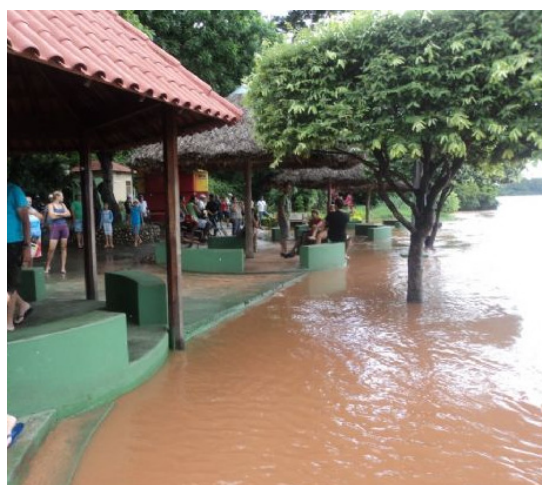

Figure 4. Flooding of Araguaia-Mar 2011

Source: http://www.olhardireto.com.br

In the previous category, the areas included in the medium vulnerability class have an extension of 7.66 square kilometers, which corresponds to $2.41 \%$ of the study area; and have a flooding frequency from 2 to 10 years. These areas are mainly occupied by buildings, and therefore the damage to the population is generally more significant when heavy rainfall occur. Figures 5 and 6 show the flood of the river in this flood spot, in 1997.

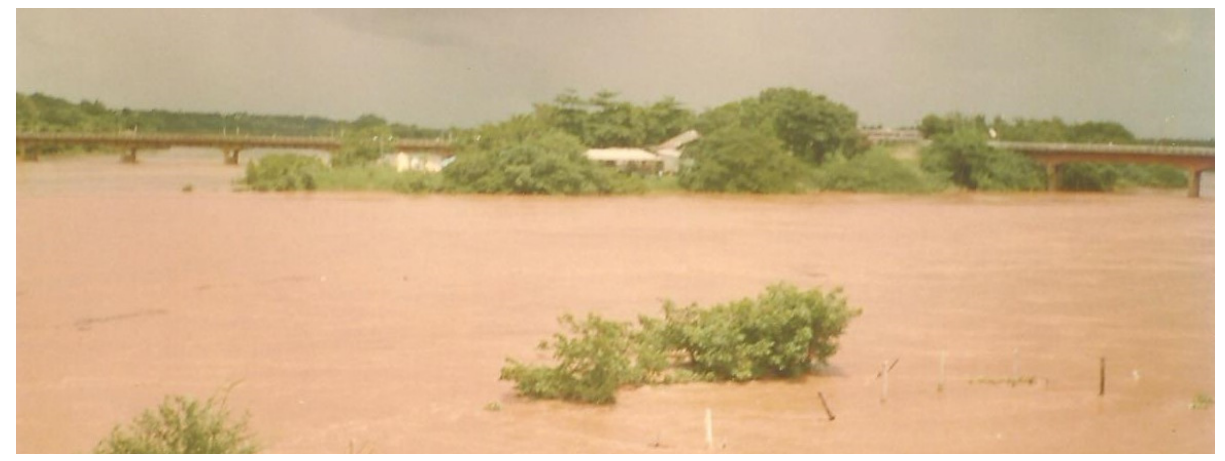

Figure 5. Flooding of Araguaia River in 1997

Source: Photo of the first author

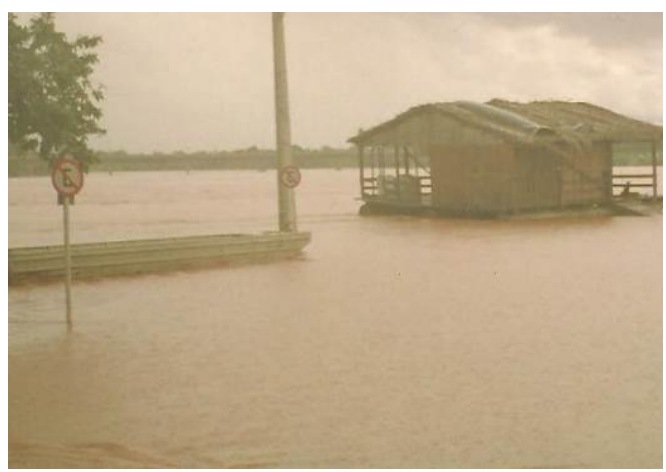

Figure 6. Flooding of Araguaia River in 1997

Source: Photo of the first author

The low vulnerability area, with a frequency of 24 years, has 11.18 square kilometers of extension relating to $3.52 \%$ of the area. It is noteworthy that the rest of the study area was characterized as very low vulnerability, corresponding to $92.57 \%$ of the study area.

As important as the boundaries of these flood spots are, it is the verification of occupations in PPAs, as it is a 
protected area besides several environmental, functions that ensures the well-being of the human population, which should also be targets of Public Policy.

\subsection{Occupation and Anthropical Interference in the PPAs}

As for the Tourism and recreation:

The tourism potential of the studied area is large, and some segments of the tourism sectors depend directly on water resources, such as fishing, beach activities, and boating activity. On the other hand, tourism can have impacts on water, like is the case of large flows of people during tourist events in the cities studied.

After analysis of occupations, three areas with greater human interference were detected, because they are areas that are exploited by tourist activities. They are:

- Area 01: Araras Beach located in the municipality of Pontal do Araguaia - MT;

- Area a 02: Salomé José Rodrigues Park (Porto do Baé) located in the municipality of Barra do Garças - MT

- Area 03: Quarto Crescente Beach located in the municipality of de Aragarças - GO.

Figure 7 shows the location of these areas.

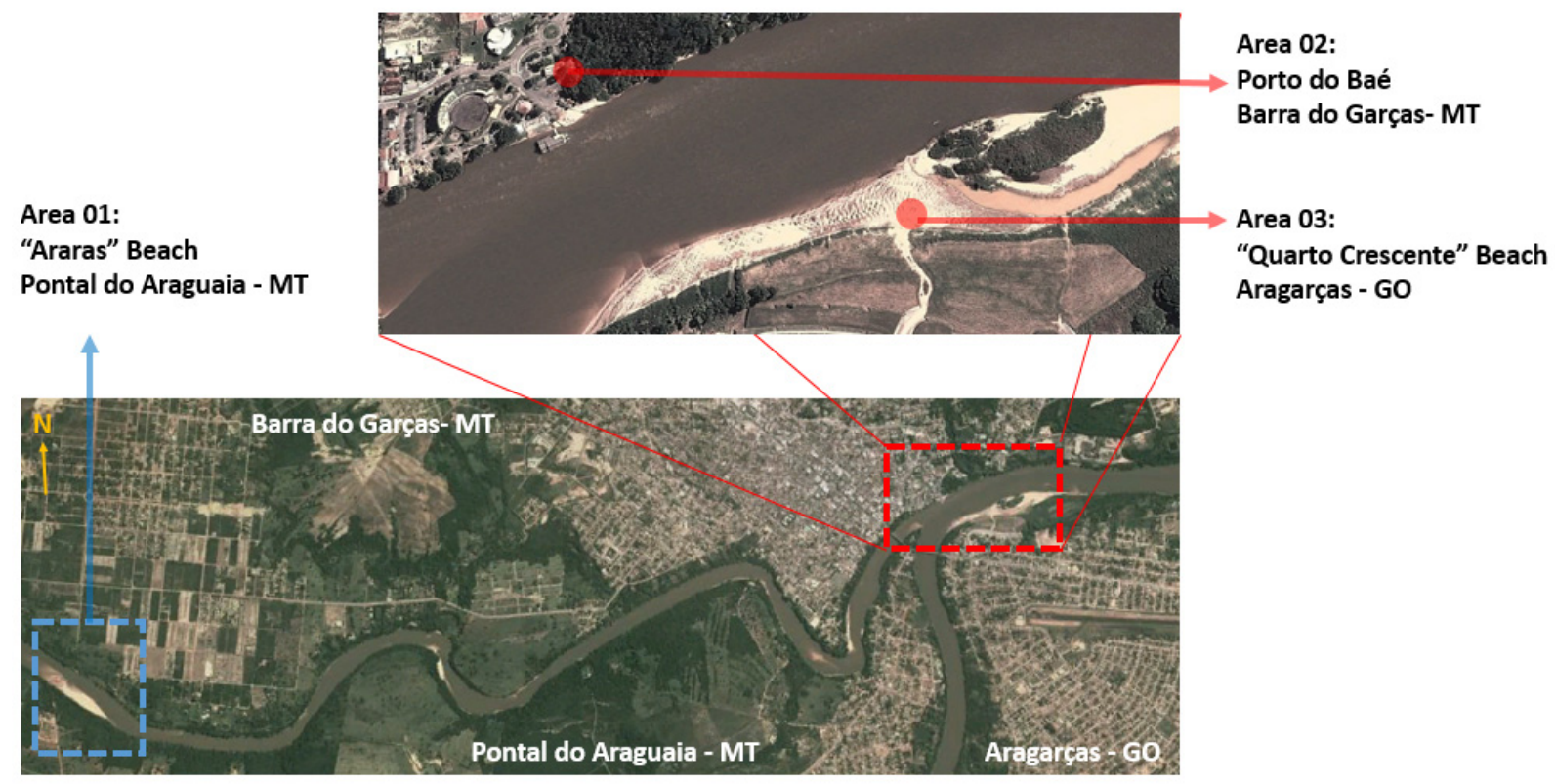

Figure 7. Location of Areas 01, 02 and 03

Source: Elaborated by the first author, from satellite image Google Earth (2014).

The Area 01 (Araras Beach) and Area 03 (Quarto Crescente Beach) have the same characteristics: a place where, in the holiday season, is occupied by tourists of the region. Even with its enhanced use in July and August, it is important to do a control of induced impacts, including environmental education and solid waste plan of the local. As an example of impacts, it is cited in intense movement in the season, since it generates solid waste and consequently water pollution. Figures $8 \mathrm{a}, 8 \mathrm{~b}$ and $9 \mathrm{a}, 9 \mathrm{~b}$, show the locations with an intense movement of tourists. 

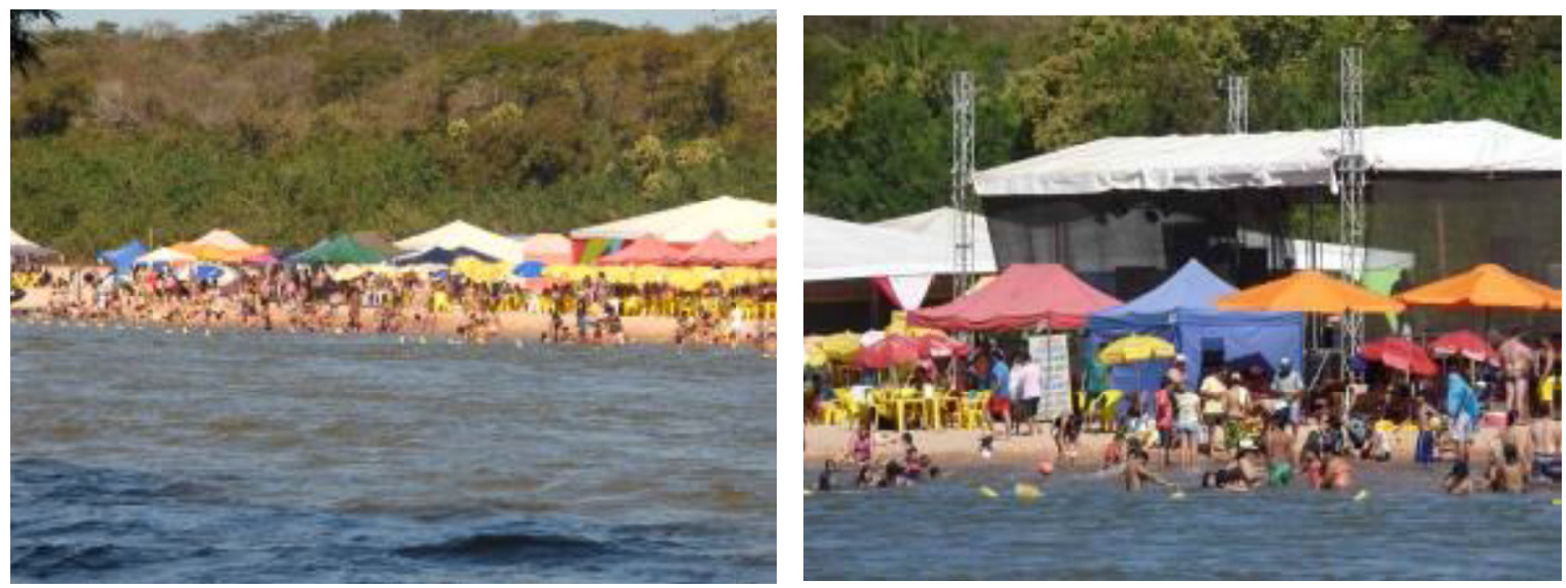

Figure 8a and 8b -Arara Beach of Garças River in July 2014

Source: Photo of the first author.
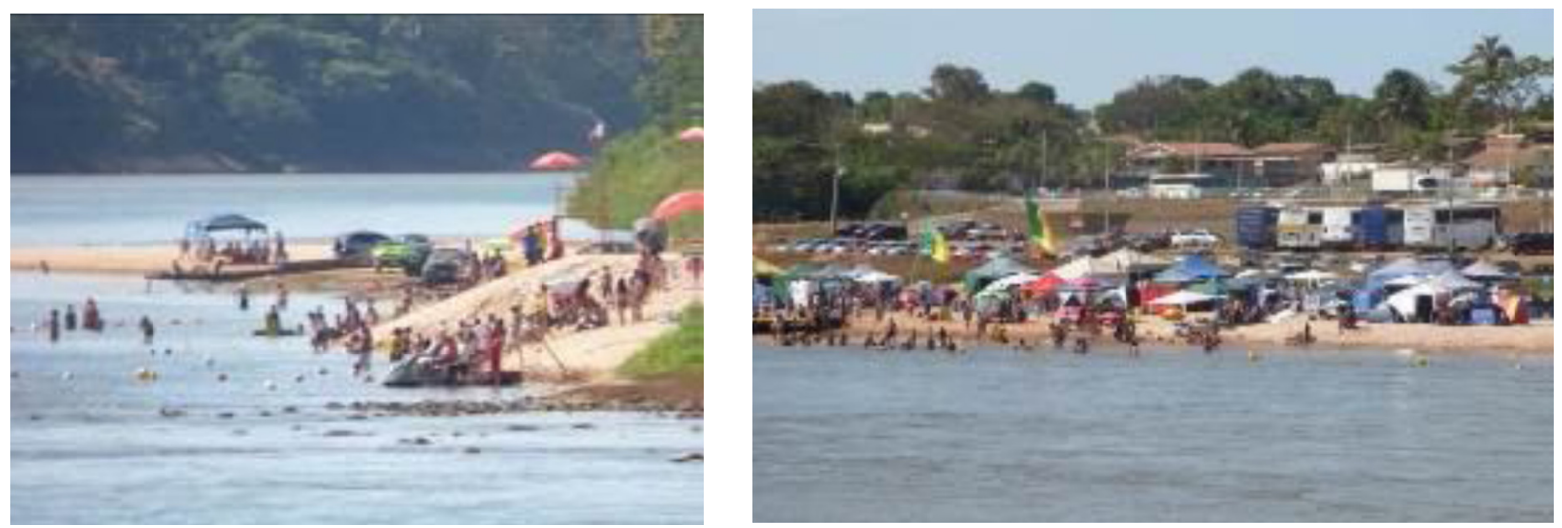

Figures 9a and 9b-Quarto Crescente Beach on the banks of the Araguaia River in Aragarças - GO

Source: Photo of the first author (2014).

In the area 02, is the Salome Jose Rodrigues Park (Porto do Baé), that is the multipurpose space, consisting of stands with an arena for events and presentations, sports court, kiosks, snack bars, a floating restaurant, access ramps for boats, a concrete stand for water events and snack bars. The intervention of the river follows the urban bias, with the presence of artificiality of them. (Figure 10a and 10b)
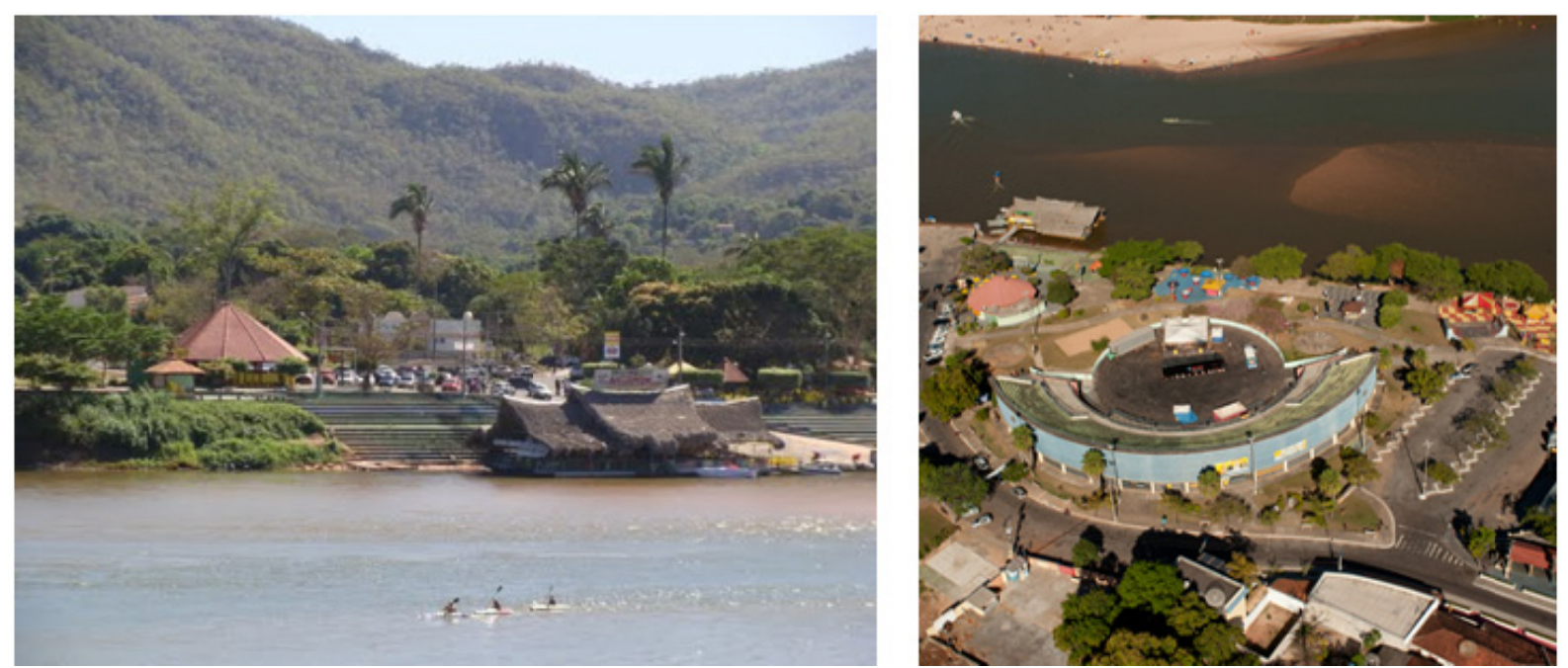

Figure 10a and 10b -Porto do Baé -Barra do Garças - MT

Source: http://www.panoramio.com 
On the subject, it is interesting to note that this artificiality, cited above, does not include integrated urban vision to environmental vision. The ideal would be that, future intervention projects, in these local, were treated by an interdisciplinary view, of course, establishing a harmonious relationship between environmental and urban aspects.

It is also highlighted that due to the heavy flow of people in the place, it's likely that solid waste is disposed of in the river, either by storm water runoff or wind. In addition, the loading and unloading of boats can contribute in some way to the erosive processes.

As for other occupations:

In relation to other occupations in the PPA areas, it is noteworthy that it was detected two areas with greater human interference:

- $\quad$ Area 04: Characterized as several isolated stretches along the Araguaia River and the Garças River with residential and commercial occupations

- $\quad$ Area 05: Characterized as an area occupied by industrial building

The Garças and Araguaia rivers have an average of 100 meters wide, in the analyzed section. And as measurement made on the satellite image, several residential and commercial buildings were built on PPA, i.e. within the area of 100 meters provided for in Article 4, I, "c" of n.12.651/2012 Law, showing therefore themselves in disagreement with the Forest Code. (Figure 11).
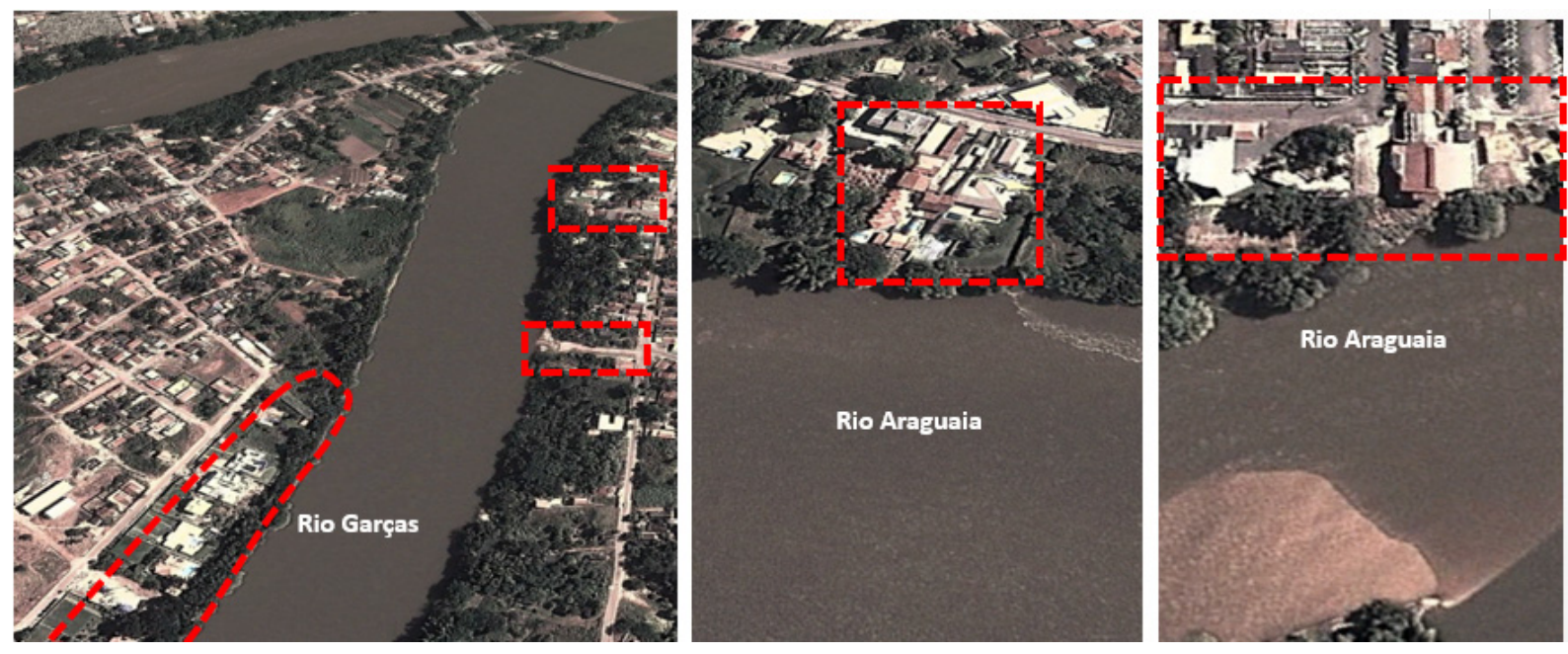

Figure 11. Area 04: Buildings built in PPAs

Source: first author construction

The area 05, demonstrated in Figure 12 shows the occupation of PPA by an industrial building - a fridge - which besides being an impactful activity, is also occupying the PPA irregularly, as is distant only 40m from the Araguaia river. 


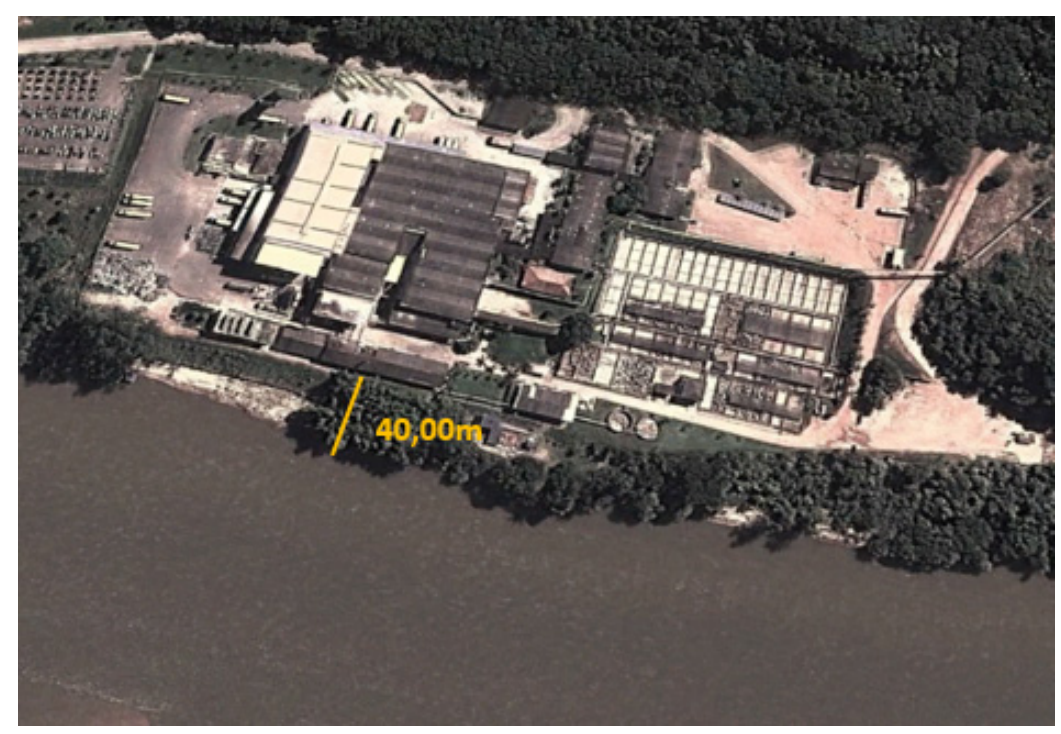

Figure 12. Industrial building implementation, with a distance of only $40 \mathrm{~m}$ from the Araguaia River

Source: first author construction

It is true that the current legislation, in particular the Forest Code, seeks to protect the areas of permanent preservation in order to prevent the degradation of these areas of great environmental importance, but at the same time shy away the occupation of these areas so that are also minimized risks of environmental damage due to flooding, which often matters in fatalities.

Thus, it is very important that the Government enforces compliance with the restrictions established by law, under the penalty of being considered an accomplice to the illegal occupation of permanent preservation areas and thus co-responsible for any tragedies involving climatic phenomena, especially in relation to flooding and also mass shifts.

\section{Final Considerations}

After the research it was possible to map areas of environmental vulnerability by floods, including determining the modes of occupation, which are inserted in Permanent Preservation Area in the study area.

This mapping can certainly contribute to the planning and management of water in the urban environment, as a tool for public policies that seek a better urban planning, regional planning and even eventual urban drainage plan, minimizing the risks to which the population is exposed.

In this sense, although the weather phenomena are almost inevitable, it is fundamentally important that preventive measures to control areas prone to flooding be implemented; but should also focus on public awareness.

Admittedly informative actions to the occupants of these vulnerable areas about the risks they face, can give greater resilience to population, as well as promoting proactive actions such as compliance with environmental legislation and proper management of solid waste produced.

It is in this context that civil society, in partnership with the academic community may also participate in this process, through cooperation activities with the Government in monitoring and implementation of good practices, which should aim directly to education, environmental preservation and obviously, inhibiting the occupation of new areas subject to flooding.

\section{References}

Brasil. (2012). Lei Federal $n^{o}$. 12651. Dispõe sobre a proteção da vegetação nativa. http://www.planalto.gov.br/ccivil_03/_ato2011-2014/2012/lei/112651.htm

Gamba, C., \& Ribeiro, W. C. (2012). Indicador e avaliação da vulnerabilidade socioambiental no município de São Paulo. GEOUSP - Espaço $e$ Tempo, $31, \quad$ 19-31. http://dx.doi.org/10.11606/issn.2179-0892.geousp.2012.74266 
Maricato, E. (2001). Brasil, cidades: alternativas para a crise urbana. Petrópolis: Vozes.

\section{Note}

Note 1. According to Article 4 of Brazilian law n. 12.652/2012 is considered Permanent Preservation Area of 100 (one hundred) meters for water courses that have 50 (fifty) to 200 (two hundred) meters wide.

\section{Copyrights}

Copyright for this article is retained by the author(s), with first publication rights granted to the journal.

This is an open-access article distributed under the terms and conditions of the Creative Commons Attribution license (http://creativecommons.org/licenses/by/4.0/). 